\title{
Obesity - a risk factor for asthma, but not for atopic dermatitis, allergic rhinitis and sensitization
}

\author{
Adam J Sybilski ${ }^{1,2, *}$, Filip Raciborski ${ }^{3}$, Agnieszka Lipiec ${ }^{1}$, Aneta Tomaszewska ${ }^{1}$, \\ Adam Lusawa ${ }^{1}$, Konrad Furmańczyk ${ }^{1}$, Edyła Krzych-Fałta ${ }^{1}$, Jarosław Komorowski ${ }^{1}$ and \\ Bolesław Samoliński ${ }^{1}$ \\ ${ }^{1}$ Department of the Prevention of Environmental Hazards and Allergology, Medical University of Warsaw, Warsaw, \\ Poland: ${ }^{2}$ Department of Pediatric and Neonatology, Central Clinical Hospital of Ministry of Internal Affair, Wołoska \\ 137, 02-507 Warsaw, Poland: ${ }^{3}$ Department of Epidemiology and Health Promotion, Institute of Rheumatology, \\ Warsaw, Poland
}

Submitted 1 October 2013: Final revision received 14 April 2014: Accepted 24 March 2014: First published online 17 April 2014

\begin{abstract}
Objective: To analyse the relationship between obesity and overweight and the prevalence of allergic diseases and sensitization, and the impact of gender and place of residence.

Design: Questionnaire based on those used in ISAAC (International Study of Asthma and Allergies in Childhood) and ECRHS (European Community Respiratory Health Survey).

Setting: Our study involved populations of the eight largest cities and one rural region in Poland (each with over 150000 inhabitants).

Subjects: The study included 18617 participants (24.2\% aged 6-7 years, $25 \cdot 4 \%$ aged 13-14 years, 50.4\% adults aged 20-44 years) in eight cities and one rural area. The out-patient study involved 4783 patients $(25.7 \%)$; we performed skin prick testing with fifteen aeroallergens.

Results: Overweight was found in $16 \cdot 13 \%$ of participants $(9 \cdot 11 \%$ of $6-7$-year-olds, $4.90 \%$ of $13-14$-year-olds and $25.61 \%$ of adults), obesity in $6.41 \%(7 \cdot 16 \%, 2.45 \%$ and $8.36 \%$, respectively). In adults, overweight $(\mathrm{OR}=1.34)$ and obesity $(\mathrm{OR}=1.80)$ increased the prevalence of asthma, especially in women $(\mathrm{OR}=1.53, \mathrm{OR}=2 \cdot 01)$. Among 13-14-year-olds the prevalence was higher only in the obese $(\mathrm{OR}=1.76)$. Overweight $(\mathrm{OR}=1.99)$ and obesity $(\mathrm{OR}=2 \cdot 17)$ affected the incidence of doctordiagnosed asthma in 6-7-year-olds. Overweight $(\mathrm{OR}=0.81)$ and obesity $(\mathrm{OR}=0.76)$ reduced the prevalence of allergic rhinitis in men. There was no relationship between BMI and asthma in people from rural areas. Obesity and overweight did not affect the frequency of sensitization to aeroallergens.

Conclusions: Overweight and obesity increased the prevalence of symptomatic asthma in adults, especially in women. In 13-14-year-olds, only obesity increased the prevalence of asthma. In children, overweight was associated with increased prevalence of clinically diagnosed and declared asthma and a trend towards atopy. Higher BMI was negatively associated with the prevalence of allergic rhinitis in overweight and obese man. There was no correlation between BMI and sensitization to aeroallergens.
\end{abstract}

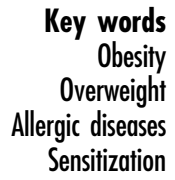

There have been trends worldwide of increased prevalence of both obesity and allergic disorders. Experimental models, several prospective cohort studies and meta-analysis have evaluated the association between obesity and allergy, mostly focusing on asthma, asthma-like symptoms and bronchial inflammation ${ }^{(1-4)}$. However, the association tends to be stronger in non-allergic or non-atopic individuals than in allergic or atopic individuals ${ }^{(5)}$. A similar trend was proven in bronchial hyperresponsiveness and atopic dermatitis ${ }^{(6-8)}$, but obesity was negatively associated with the prevalence of allergic rhinitis or there was no relationship ${ }^{(8-10)}$. Gender is also likely to be important when examining the relationship between allergic disease and obesity in children and adults, but the evidence is inconclusive. Some data showed a relationship of obesity and asthma only in females. Among a number of studies that have been conducted among children and adults, some have demonstrated an increased risk of atopy among overweight or obese individuals ${ }^{(11,12)}$, while others have found no association between adiposity and atopy $^{(13,14)}$. 
The objective of the present study, a part of the Epidemiology of Allergic Disorders in Poland study (ECAP), was to analyse the association between the different BMI categories (normal weight, overweight and obesity) and allergic diseases and sensitization in a population of Polish children aged 6-7 years and 13-14 years and adults aged 20-44 years.

\section{Materials and methods}

\section{Study population}

ECAP used the methodology of the International Study of Asthma and Allergies in Childhood (ISAAC) and the European Community Respiratory Health Survey (ECRHS). The study areas were selected according to the ECRHS guidelines. ECAP involved the populations of the eight largest urban agglomerations in Poland (each with over 150000 inhabitants) and additionally one rural region, also with a population of over 150000 inhabitants since the rural population accounts for $39 \%$ of the entire Polish population. The study areas were chosen specifically but the study participants were selected by stratified random sampling based on the national identification number PESEL. In accordance with the ISAAC and ECRHS protocols, the study included three groups of respondents: children aged 6-7 years and 13-14 years, and adults (aged 20-44 years).

The first part of the project (a questionnaire survey) was carried out on a group of 22703 participants with the response rate of $64.4 \%$ and eventually 18617 completed questionnaires were accepted. It involved two age groups of children, 6-7-year-olds and 13-14-year-olds, and adults. There were 4510 (24.2\%) 6-7-year-olds, 4721 (25.4\%) 13-14-year-olds and $9386(50 \cdot 4 \%)$ adults. Of the respondents, 10011 (53.8\%) were female and 8606 (46.2\%) were male. In the medical evaluation part of the study, 4783 patients (25.7\% of the respondents) were assessed on an out-patient basis, including 1329 aged 6-7 years, 1321 aged $13-14$ years and 2133 adults. The study group design is shown in Table 1.

\section{Questionnaire-based survey}

The questionnaire was based on the translated and validated questionnaires used in ECRHS and ISAAC. The diagnosis of allergic diseases was based on the assumptions of these studies described in detail in previous reports ${ }^{(15)}$. Details of the definition of the diseases are shown in the Appendix.

\section{Medical evaluation}

Allergologists diagnosed asthma according to the GINA (Global Initiative for Asthma) criteria, allergic rhinitis using the ARIA (Allergic Rhinitis and its Impact on Asthma) criteria and atopic dermatitis using the Hanifin and Rajka criteria. Skin prick testing (SPT) was performed for fifteen of the most common air-borne allergens (Allergopharma, Reinbek, Germany) such as: hazel (Corylus spp.); alder (Alnus spp.); birch (Betula spp.); grasses/crop plants; rye (Secale cereal); mugwort (Artemisia spp.); plantain (Plantago spp.); Alternaria, Cladosporium and perennial allergens, including moulds I (Alternaria tenis, Botrylis cinerea, Cladosporium herbarum, Culvularia lanata, Fusarium moniliforme, Helminthosporium) and moulds II (Aspergillus fumigatus, Mucor mucedo, Penicillium notatum, Rhizopus nigricans, Serpula lacrymans, Pullularia pullulans); common species of mites (Dermatophagoides pteronyssinus and Dermatophagoides farinae); and dog and cat dander. The test was considered negative when the wheal size was $<3 \mathrm{~mm}$, positive when the wheal size was 3-5 $\mathrm{mm}$ and markedly positive when the wheal size was $\geq 6 \mathrm{~mm}$. Positive SPT for at least one allergen indicated atopy.

\section{Anthropometric measurements}

In all participants included in the study, the anthropometric parameters were obtained by a questionnaire. Parents of 6-7-year-olds, 13-14-year-olds and adults recorded the body weight (to nearest $0.1 \mathrm{~kg}$ ) and height (to nearest $0.5 \mathrm{~cm}$ ). In those participating in the out-patient study, we measured weight without shoes or outer clothing (to nearest $0 \cdot 1 \mathrm{~kg}$ ) and height (to nearest $0 \cdot 1 \mathrm{~cm}$ ). BMI was calculated as weight $/$ height $^{2}\left(\mathrm{~kg} / \mathrm{m}^{2}\right)$. BMI was analysed as a categorical variable divided into three categories (normal weight, overweight and obesity). According to

Table 1 Baseline characteristics of the study population, part of the Epidemiology of Allergic Disorders in Poland study (ECAP)

\begin{tabular}{|c|c|c|c|c|c|c|c|c|}
\hline & \multicolumn{2}{|c|}{ Total } & \multicolumn{2}{|c|}{ 6-7-year-olds } & \multicolumn{2}{|c|}{ 13-14-year-olds } & \multicolumn{2}{|c|}{ 20-44-year-olds } \\
\hline & $n$ & $\%$ & $n$ & $\%$ & $n$ & $\%$ & $n$ & $\%$ \\
\hline \multicolumn{9}{|c|}{ Questionnaire survey } \\
\hline Total & 18617 & $100 \cdot 0$ & 4510 & $24 \cdot 2$ & 4721 & $25 \cdot 4$ & 9386 & $50 \cdot 4$ \\
\hline Female & 10011 & $53 \cdot 8$ & 2218 & $22 \cdot 2$ & 2275 & $22 \cdot 7$ & 5518 & $55 \cdot 1$ \\
\hline Male & 8606 & $46 \cdot 2$ & 2292 & $26 \cdot 6$ & 2446 & $28 \cdot 4$ & 3868 & 44.9 \\
\hline Urban region & 16562 & $89 \cdot 0$ & 4048 & $24 \cdot 4$ & 4177 & $25 \cdot 2$ & 8337 & $50 \cdot 3$ \\
\hline Rural region & 2055 & $11 \cdot 0$ & 462 & $22 \cdot 5$ & 544 & $26 \cdot 5$ & 1049 & $51 \cdot 0$ \\
\hline \multicolumn{9}{|c|}{ Medical evaluation } \\
\hline Total & 4783 & $100 \cdot 0$ & 1329 & $27 \cdot 8$ & 1321 & $27 \cdot 6$ & 2133 & 44.6 \\
\hline Female & 2608 & 54.5 & 657 & $25 \cdot 2$ & 639 & 24.5 & 1312 & $50 \cdot 3$ \\
\hline Male & 2175 & $45 \cdot 5$ & 672 & 30.9 & 682 & 31.4 & 821 & $37 \cdot 7$ \\
\hline Urban region & 4242 & 88.7 & 1173 & $27 \cdot 7$ & 1149 & $27 \cdot 1$ & 1916 & $45 \cdot 2$ \\
\hline Rural region & 545 & 11.4 & 156 & $28 \cdot 6$ & 172 & 31.6 & 217 & 39.8 \\
\hline
\end{tabular}


the accepted definition in epidemiological studies, adult obesity was defined as BMI $\geq 30 \cdot 0 \mathrm{~kg} / \mathrm{m}^{2}$, overweight as $\mathrm{BMI}=25 \cdot 0-29 \cdot 9 \mathrm{~kg} / \mathrm{m}^{2}$ and normal weight as $\mathrm{BMI}=18.5$ $-24.9 \mathrm{~kg} / \mathrm{m}^{2(9,16)}$. Children's BMI referred to the new Polish growth charts (OLAF Study) ${ }^{(17)}$ and obesity was diagnosed when BMI was $>95$ th percentile, overweight when BMI was $>85$ th and $<95$ th percentile and normal weight when BMI was $>3$ rd and $<85$ th percentile.

\section{Statistical evaluation}

A $\chi^{2}$ test or Fisher's exact test (for small sample sizes) was used in the statistical analysis. To determine the strength of association and the dependence between variables, $\chi^{2}$ statistics and odds ratios were calculated. Results were considered to be statistically significant at $P<0.05$.

\section{Etbics}

The study was approved by the institutional Bioethics Committee. It was carried out as part of the project 'Implementation of the system for prevention and early diagnosis of allergic disorders in Poland' (No. 6 P05 2005 C/06572) funded by the Minister for Health and the Minister for Science.

\section{Results}

The prevalence of obesity and overweight and of allergic diseases and sensitization in the study population is shown in Table 2.

Among adults (based on the questionnaire), a more frequent presence of symptomatic asthma was significantly associated with being overweight (OR=1.34; $P<0.0001)$ and obese $(\mathrm{OR}=1.80 ; \quad P<0.0001)$. In 13-14-year-olds symptomatic asthma was more frequent only in the obese (OR=1.76; $P=0.017$ ). Being overweight was significantly associated with an increased prevalence of declared asthma in 6-7-year-olds $(\mathrm{OR}=2 \cdot 44 ; P<0 \cdot 0001)$ and 13-14-year-olds (OR $=1.66 ; P=0.016)$. Obese patients had no increase of declared asthma. Data based on medical evaluation showed that being overweight $(\mathrm{OR}=1.99 ; P=0.032)$ and obese
(OR $=2.17 ; P=0.031)$ were associated with an increased occurrence of asthma just in 6-7-year-old children. An increased prevalence of sensitization was only found in obese children aged $6-7$ years $(\mathrm{OR}=1 \cdot 84 ; P=0 \cdot 017)$. Detailed data are shown in Table 3 .

When we divided the patients into two groups: sensitized to seasonal (positive SPT just for seasonal aeroallergens) and perennial (positive SPT just for perennial aeroallergens) aeroallergens, we found no effect of being overweight and obese on the prevalence of sensitization. We also found no effect of being overweight and obesity on monovalent $v$. polyvalent atopy (data not presented).

In adults, there was a significantly higher prevalence of symptomatic asthma in overweight $(\mathrm{OR}=1.53 ; P<0.001)$ and obese $(\mathrm{OR}=2.01 ; P<0.001)$ females (Table $4(\mathrm{a})$ ). Among 13-14-year-olds, the same significance and tendency were also seen only in obese girls $(\mathrm{OR}=2 \cdot 25$; $P=0.026$ ). In adults, overweight (OR $=0.81 ; P=0.015$ ) and obese $(\mathrm{OR}=0.76 ; P<0.05)$ males had a significantly decreased prevalence of allergic rhinitis.

Among participants from urban areas, the prevalence of symptomatic asthma was significantly higher in overweight $(\mathrm{OR}=1.36 ; \quad P<0.01)$ and obese $(\mathrm{OR}=1.88$; $P<0.01)$ adults and obese 13-14-year-olds (OR $=2 \cdot 07$; $P<0.01)$. Similar correlations were not observed in inhabitants from rural areas. In rural adult inhabitants, being overweight was associated with a decreased prevalence of allergic rhinitis $(\mathrm{OR}=0.59 ; P=0.02$; Table $4(\mathrm{~b})$ ).

\section{Discussion}

To our knowledge, the present study is first and largest one in this part of Europe assessing the relationship between overweight and obesity and the prevalence of allergic diseases and sensitization among children and adults, using data from a large questionnaire-based survey. The data were collected from almost 20000 participants and additionally from medical evaluation of more than

Table 2 Prevalence of obesity, overweight and allergic diseases and sensitization in the study population, part of the Epidemiology of Allergic Disorders in Poland study (ECAP)

\begin{tabular}{|c|c|c|c|c|c|c|c|c|}
\hline & Total & $\begin{array}{l}\text { 6-7-year- } \\
\text { olds }\end{array}$ & $\begin{array}{l}\text { 13-14-year- } \\
\text { olds }\end{array}$ & $\begin{array}{c}\text { 20-44-year- } \\
\text { olds }\end{array}$ & Female & Male & $\begin{array}{l}\text { Urban } \\
\text { region }\end{array}$ & $\begin{array}{l}\text { Rural } \\
\text { region }\end{array}$ \\
\hline Overweight & $16 \cdot 13$ & $9 \cdot 11$ & 4.90 & $25 \cdot 61$ & $11 \cdot 78$ & 21.85 & $16 \cdot 27$ & $17 \cdot 73$ \\
\hline Obesity & $6 \cdot 41$ & $7 \cdot 16$ & $2 \cdot 45$ & $8 \cdot 36$ & $5 \cdot 15$ & 8.24 & $6 \cdot 38$ & $8 \cdot 17$ \\
\hline Declared asthma & 4.62 & 4.41 & $6 \cdot 22$ & 4.02 & 3.98 & $5 \cdot 37$ & 4.84 & $2 \cdot 87$ \\
\hline Symptomatic asthma & $15 \cdot 71$ & $19 \cdot 23$ & $15 \cdot 91$ & 13.80 & $12 \cdot 71$ & $14 \cdot 36$ & 14.01 & $9 \cdot 15$ \\
\hline Clinically diagnosed asthma & $10 \cdot 56$ & 11.44 & 11.36 & 9.52 & $9 \cdot 24$ & $12 \cdot 14$ & $10 \cdot 62$ & 10.09 \\
\hline Allergic rhinitis & $21 \cdot 11$ & $23 \cdot 72$ & 24.57 & 21.01 & $21 \cdot 22$ & 24.03 & $23 \cdot 33$ & $15 \cdot 96$ \\
\hline Clinically diagnosed allergic rhinitis & 28.29 & $23 \cdot 78$ & 30.05 & 30.00 & $26 \cdot 42$ & 30.53 & 28.34 & 27.89 \\
\hline Atopic dermatitis & 3.91 & $5 \cdot 34$ & $4 \cdot 30$ & 3.02 & 4.61 & 3.08 & $4 \cdot 12$ & 1.90 \\
\hline Clinically diagnosed atopic dermatitis & $6 \cdot 50$ & 8.73 & 9.01 & 3.56 & $6 \cdot 75$ & $6 \cdot 21$ & $6 \cdot 87$ & 3.67 \\
\hline Sensitization & $45 \cdot 81$ & $39 \cdot 31$ & 48.62 & $48 \cdot 22$ & 42.94 & 49.29 & 43.46 & 64.22 \\
\hline $\mathrm{SPT} \geq 6 \mathrm{~mm}$ & $22 \cdot 02$ & $13 \cdot 22$ & $25 \cdot 54$ & 25.41 & 17.91 & 26.99 & 23.88 & $7 \cdot 71$ \\
\hline
\end{tabular}

SPT, skin prick test.

Data are presented as percentages. 
4500 out-patients. The study was conducted in accordance with the standards of ISAAC and ECRHS and due to the Polish specificity (rural residents constitute 39\% of the Polish population) included one rural area.

In the literature, there are conflicting reports about the influence of BMI on allergic status. At the present state of knowledge, it appears that no study has confirmed objective evidence for the association, and results might be due to increased reporting of symptoms in obese individuals or to diagnostic bias. Similar contradictory results were also found for BMI and atopy. Our study confirmed previous reports of cross-sectional epidemiological studies that being overweight and obese is associated with an increased risk of asthma in adults (especially symptomatic asthma). Additionally, the adverse effect increased with increasing BMI: being obese compared with being overweight substantially increased the risk of asthma. Several investigations have already shown that the relationship between obesity and asthma is more likely to be observed among females, which is consistent with our present finding. It has been speculated that female sex hormones may contribute to the increased risk of asthma in obesity, although the precise mechanisms remain to be elucidated $^{(18)}$. Confirmation of the profound impact of environmental factors and lifestyle on the development of asthma was our finding of the relationship between being overweight and obese and the prevalence of asthma only in urban residents. There was no such trend in the rural population. This could be due to the representation of the rural inhabitants, who accounted for approximately $20 \%$ of our study population; this is relatively low compared with the true percentage of the entire Polish population and the proportion of the urban population. The second reason for such a result could be the fact that in addition to a high BMI increasing the prevalence of asthma, other environmental factors could also play a role (e.g. air pollution, smoking and lifestyle). Further detailed study is required to analyse the impact of obesity and overweight in allergic diseases in rural populations.

In 6-7-year-old children, based on a questionnaire survey, we confirmed no correlation between obesity and asthma, but there was a statistically significant increased prevalence of clinically diagnosed asthma. In overweight children, there was an increased occurrence of clinically diagnosed asthma and declared asthma. This finding, as well as a trend towards atopy in this group, is also supported by the significant association with SPT $\geq 6 \mathrm{~mm}$. It seems that this discrepancy may be due to underdiagnosis of asthma in the Polish population, which was recorded in ECAP and presented in previous reports ${ }^{(19)}$.

Although the association between obesity and asthma has been gaining more attention, few studies have been conducted concerning the relationship between obesity and other allergic diseases. The results are ambiguous and often contradictory. Most of the published studies suggest that being overweight and obese has a positive association with atopic dermatitis in children and adults ${ }^{(6-8,10,20,21)}$. 
Table 4 Association of different BMI categories with the prevalence of allergic diseases and sensitization according to gender (a) and place of residence (b), study population part of the Epidemiology of Allergic Disorders in Poland study (ECAP)

\begin{tabular}{|c|c|c|c|c|c|c|c|c|c|c|c|c|}
\hline & \multicolumn{4}{|c|}{ 6-7-year-olds } & \multicolumn{4}{|c|}{ 13-14-year-olds } & \multicolumn{4}{|c|}{ 20-44-year-olds } \\
\hline & \multicolumn{2}{|c|}{ Overweight } & \multicolumn{2}{|r|}{ Obesity } & \multicolumn{2}{|c|}{ Overweight } & \multicolumn{2}{|r|}{ Obesity } & \multicolumn{2}{|c|}{ Overweight } & \multicolumn{2}{|r|}{ Obesity } \\
\hline & OR & $95 \% \mathrm{Cl}$ & OR & $95 \% \mathrm{Cl}$ & OR & $95 \% \mathrm{Cl}$ & OR & $95 \% \mathrm{Cl}$ & OR & $95 \% \mathrm{Cl}$ & OR & $95 \% \mathrm{Cl}$ \\
\hline \multicolumn{13}{|l|}{ (a) } \\
\hline \multicolumn{13}{|l|}{ Declared asthma } \\
\hline Female & $1 \cdot 76$ & $0.83,3.73$ & 1.39 & $0.57,3.38$ & 1.40 & $0.59,3.29$ & $1 \cdot 25$ & $0.38,4.09$ & $1 \cdot 33$ & $0.94,1.90$ & $1 \cdot 31$ & $0.77,2.22$ \\
\hline Male & 1.45 & $0.83,2.55$ & 0.97 & $0.49,1.93$ & $1 \cdot 12$ & $0.59,2.13$ & 0.54 & $0.16,1.74$ & 0.94 & $0.67,1.33$ & 0.99 & $0.59,1.63$ \\
\hline \multicolumn{13}{|c|}{ Symptomatic asthma } \\
\hline Female & $1 \cdot 30$ & $0.88,1.92$ & 1.37 & $0.90,2.08$ & 0.73 & $0.31,1.70$ & 2.25 & $1.07,4.72$ & 1.53 & $1.24,1.89$ & 2.01 & $1.51,2.68$ \\
\hline Male & 1.67 & $0.81,1.66$ & $1 \cdot 15$ & $0.79,1.67$ & $1 \cdot 36$ & $0.82,2 \cdot 26$ & 1.63 & $0.86,3.07$ & $1 \cdot 20$ & $0.97,1.48$ & 1.51 & $1.14,2.01$ \\
\hline \multicolumn{13}{|c|}{ Clinically diagnosed asthma } \\
\hline Female & $1 \cdot 33$ & $0.44,4.00$ & 2.70 & $1 \cdot 19,6 \cdot 13$ & 0.43 & $0.05,3.27$ & 0.60 & $0.07,4.67$ & 0.96 & $0.58,1.61$ & 1.50 & $0.76,2.95$ \\
\hline Male & 0.68 & $0.28,1.68$ & 1.00 & $0.45,2 \cdot 24$ & $1 \cdot 37$ & $0.61,3.05$ & 0.43 & $0.05,3.34$ & 1.05 & $0.64,1.72$ & 0.54 & $0.22,1.31$ \\
\hline \multicolumn{13}{|l|}{ Allergic rhinitis } \\
\hline Female & 0.80 & $0.53,1.19$ & 0.82 & $0.53,1.26$ & 1.07 & $0.64,1.78$ & 1.43 & $0.76,2.69$ & 0.96 & $0 \cdot 80,1 \cdot 15$ & 0.92 & $0.70,1.22$ \\
\hline Male & $1 \cdot 26$ & $0.91,1.74$ & $1 \cdot 22$ & $0.87,1.71$ & $1 \cdot 14$ & $0.78,1.66$ & 1.07 & $0.64,1.79$ & 0.81 & $0.68,0.96$ & 0.76 & $0.59,0.99$ \\
\hline Clinically diagnos & & & & & & & & & & & & \\
\hline Female & 1.90 & $0.94,3.86$ & 1.59 & $0.81,3 \cdot 11$ & 0.80 & $0 \cdot 29,2 \cdot 21$ & 1.64 & $0.58,4.58$ & 0.81 & $0.58,1.14$ & $1 \cdot 12$ & $0.68,1.82$ \\
\hline Male & $1 \cdot 30$ & $0.69,2.45$ & $1 \cdot 14$ & $0.59,2.20$ & 1.07 & $0.57,2.02$ & 2.02 & $0.74,5.46$ & 0.95 & $0.68,1.31$ & $1 \cdot 15$ & $0.73,1.82$ \\
\hline Atopic dermatitis & & & & & & & & & & & & \\
\hline Female & 1.60 & $0.33,7.69$ & & TSS & 0.24 & $0.03,1.52$ & 0.73 & $0.06,8.37$ & 1.51 & $0.77,2.69$ & 1.00 & $0.38,2.65$ \\
\hline Male & $5 \cdot 10$ & $0.6,42 \cdot 13$ & 2.55 & $0.51,12.54$ & 0.73 & $0.20,2.56$ & 0.58 & $0.05,6.77$ & 0.84 & $0.38,1.85$ & $1 \cdot 11$ & $0.39,3.16$ \\
\hline Clinically diagno & & & & & & & & & & & & \\
\hline Female & $1 \cdot 23$ & $0.41,3.70$ & 0.72 & $0.21,2.48$ & & TSS & $1 \cdot 20$ & $0.26,5.42$ & 0.70 & $0.31,1.58$ & $1 \cdot 10$ & $0.38,3.15$ \\
\hline Male & 1.90 & $0.83,4.36$ & 0.43 & $0.10,1.87$ & 0.80 & $0 \cdot 24,2 \cdot 71$ & 2.67 & $0.73,9.74$ & 2.56 & $0.88,7.46$ & & TSS \\
\hline Sensitization & & & & & & & & & & & & \\
\hline Female & $1 \cdot 35$ & $0 \cdot 70,2 \cdot 61$ & 2.07 & $1 \cdot 14,3.75$ & $1 \cdot 12$ & $0.47,2.64$ & 1.04 & $0.38,2 \cdot 85$ & $1 \cdot 28$ & $0.95,1.72$ & $1 \cdot 12$ & $0.71,1.77$ \\
\hline Male & 0.91 & $0.50,1.65$ & $1 \cdot 15$ & $0.63,2.08$ & $1 \cdot 14$ & $0.62,2.08$ & 1.46 & $0.52,4.07$ & 0.98 & $0.73,1.33$ & 0.84 & $0.54,1.29$ \\
\hline $\mathrm{SPT}>6 \mathrm{~mm}$ & & & & & & & & & & & & \\
\hline Female & $1 \cdot 15$ & $0.42,3.11$ & $1 \cdot 13$ & $0.45,2.83$ & 0.98 & $0.32,2.69$ & 1.02 & $0.28,3.64$ & 0.89 & $0.62,1.29$ & $1 \cdot 24$ & $0.73,2.09$ \\
\hline Male & 0.97 & $0.43,2 \cdot 17$ & $1 \cdot 18$ & $0.54,2.55$ & 0.63 & $0.31,1.26$ & $1 \cdot 20$ & $0.43,3.35$ & 0.93 & $0.67,1.28$ & 0.98 & $0.61,1.56$ \\
\hline (b) & & & & & & & & & & & & \\
\hline Declared asthma & & & & & & & & & & & & \\
\hline Urban region & $1 \cdot 80$ & $1 \cdot 13,2 \cdot 86$ & $1 \cdot 38$ & $0.80,2.38$ & $1 \cdot 31$ & $0 \cdot 78,2 \cdot 19$ & 0.83 & $0.36,1.92$ & $1 \cdot 24$ & $0.97,1.590$ & $1 \cdot 24$ & $0.85,1.80$ \\
\hline Rural region & 0.32 & $0.04,2.56$ & & TSS & & TSS & & TSS & & TSS & & TSS \\
\hline Symptomatic ast & & & & & & & & & & & & \\
\hline Urban region & $1 \cdot 28$ & $0.97,1.68$ & $1 \cdot 25$ & $0.93,1.68$ & $1 \cdot 11$ & $0.71,1.73$ & 2.07 & $1 \cdot 27,3.37$ & 1.36 & $1.17,1.58$ & 1.88 & $1.53,2.32$ \\
\hline Rural region & 0.91 & $0.33,2.52$ & 1.57 & $0.66,3.75$ & 1.52 & $0.33,6.89$ & & TSS & $1 \cdot 27$ & $0.79,2.03$ & 0.87 & $0.40,1.89$ \\
\hline Clinically diagno & & & & & & & & & & & & \\
\hline $\begin{array}{l}\text { Urban region } \\
\text { Rural region }\end{array}$ & 1.00 & $\begin{array}{l}0.48,2.08 \\
\text { TSS }\end{array}$ & $1 \cdot 80$ & $\begin{array}{l}0.99,3.26 \\
\text { TSS }\end{array}$ & 0.95 & $\begin{array}{l}0 \cdot 42,2 \cdot 14 \\
\text { TSS }\end{array}$ & 0.51 & $\begin{array}{l}0 \cdot 12,2 \cdot 19 \\
\text { TSS }\end{array}$ & 1.07 & $\begin{array}{l}0.75,1.52 \\
\text { TSS }\end{array}$ & 1.00 & $\begin{array}{l}0.57,1.73 \\
\text { TSS }\end{array}$ \\
\hline Allergic rhinitis & & & & & & & & & & & & \\
\hline Urban region & 1.03 & $0.79,1.35$ & $1 \cdot 14$ & $0.86,1.51$ & 1.05 & $0.76,1.45$ & $1 \cdot 16$ & $0.76,1.77$ & 0.92 & $0.81,1.04$ & 0.87 & $0.71,1.06$ \\
\hline Rural region & $1 \cdot 16$ & $0.54,2.46$ & 0.55 & $0 \cdot 22,1 \cdot 38$ & 2.53 & $1 \cdot 00,6 \cdot 62$ & 1.93 & $0.58,6.41$ & 0.59 & $0.37,0.93$ & 0.73 & $0.38,1.40$ \\
\hline Clinically diagn & & & & & & & & & & & & \\
\hline Urban region & 1.43 & $0.86,2 \cdot 38$ & 1.45 & $0.89,2.37$ & 0.92 & $0.52,1.62$ & 1.62 & $0.78,3.36$ & 0.93 & $0.73,1.17$ & $1 \cdot 18$ & $0.84,1.67$ \\
\hline Rural region & 2.58 & $0.71,9.37$ & & TSS & & TSS & & TSS & 0.86 & $0.43,1.72$ & 1.05 & $0.39,2.80$ \\
\hline Atopic dermatitis & & & & & & & & & & & & \\
\hline Urban region & 2.57 & $0.73,9.03$ & $2 \cdot 25$ & $0.49,10.36$ & 0.51 & $0.19,1.39$ & & TSS & 0.99 & $0.60,1.63$ & 0.84 & $0.42,1.77$ \\
\hline Rural region & & TSS & & TSS & & TSS & & TSS & & TSS & & TSS \\
\hline Clinically diagno & & & & & & & & & & & & \\
\hline Urban region & 1.57 & $0.79,3.13$ & 0.61 & $0.23,1.56$ & 0.46 & $0.14,1.50$ & $1 \cdot 75$ & $0.65,4.67$ & 0.82 & $0.45,1.50$ & & TSS \\
\hline Rural region & & TSS & & TSS & & TSS & & TSS & & TSS & & TSS \\
\hline Sensitization & & & & & & & & & & & & \\
\hline Urban region & 1.08 & $0.67,1.75$ & 1.51 & $0.96,2.36$ & 1.06 & $0.63,1.78$ & $1 \cdot 21$ & $0.59,2.48$ & $1 \cdot 16$ & $0.94,1.44$ & 1.08 & $0.77,1.49$ \\
\hline Rural region & 1.03 & $0 \cdot 25,4 \cdot 26$ & & TSS & & TSS & & TSS & 1.50 & $0.77,2.91$ & 0.67 & $0.27,1.67$ \\
\hline $\mathrm{SPT} \geq 6 \mathrm{~mm}$ & & & & & & & & & & & & \\
\hline Urban region & $1 \cdot 13$ & $\begin{array}{l}0 \cdot 60,2 \cdot 12 \\
\text { TSS }\end{array}$ & $1 \cdot 23$ & $\begin{array}{l}0.68,2.23 \\
\text { TSS }\end{array}$ & 0.80 & $0.44,1.46$ & 0.87 & $0.38,1.98$ & $1 \cdot 12$ & $0.88,1.42$ & $1 \cdot 30$ & $0.92,1.86$ \\
\hline Rural region & & TSS & & TSS & & TSS & & TSS & 0.63 & $0 \cdot 19,2 \cdot 03$ & & TSS \\
\hline
\end{tabular}

SPT, skin prick test; TSS, too small sample.

Reference category is normal weight. Statistically significant values are shown in bold.

However, there are also reports of the non-existence of such a relationship ${ }^{(13,22)}$, which is consistent with our results. We found no effect of higher BMI on the prevalence of atopic dermatitis in children and adults, as well as in men and women, and urban and rural inhabitants.
Another interesting and unexpected finding of our study was that being overweight and obese had a negative association with rhinitis prevalence in males 20-44 years of age. The odds ratio for occurrence of allergic rhinitis in overweight men was $0 \cdot 81$, but the risk was even lower in obese men 
$(\mathrm{OR}=0.76)$. Of note, similar results were obtained in the Japanese population in adults $^{(9)}$ and schoolchildren ${ }^{(10)}$. These results may support our findings of opposing effects of obesity on asthma and rhinitis. The explanation for this phenomenon may be found in the results of the study by Johnston et $a l^{(23)}$, who showed enhanced airway responsiveness with attenuation of airway inflammation in obese mice. These observations were confirmed by Yoo et $a .^{(24)}$, who indicated an increased bronchial hyperresponsiveness in obese patients. In addition, at the same time, obesity is associated with increased breathing effort, decreased physical activity and poorer skill performance, which could also cause the development and exacerbation of asthma.

The lack of an association between adiposity and atopic sensitization, which has also been observed in our and other studies ${ }^{(13,14,20)}$, suggests that the underlying biological pathway of development of asthma may involve non-immunological mechanisms.

Also, some confirmation of this assumption is the study by Chen et al. ${ }^{(5)}$. Their results demonstrated that the association between increased BMI and asthma was stronger among non-allergic adults compared with allergic adults. If one assumes that those without a history of allergy are less likely to have allergic asthma, Chen's observations suggest that obesity has a stronger relationship with non-allergic than allergic asthma. On the other hand, we have the results of several research groups that indicate a significant association between obesity and atopic sensitization ${ }^{(1,13,24)}$. It seems that the mechanisms for atopic sensitization associated with obesity need to be explored, and further cross-sectional studies are required.

\section{Conclusion}

In conclusion, our cross-sectional study using the ISAAC and ECRHS standards showed that being overweight and obese is associated with an increased prevalence of symptomatic asthma in adults, especially in women. This correlation was only observed in obese 13-14-year-olds. Being overweight in the 6-7-year-old group was associated with an increased prevalence of clinically diagnosed asthma and declared asthma and a trend towards atopy. Higher BMI was negatively associated with the occurrence of allergic rhinitis in overweight and obese men. Being overweight and obese were not significant factors in increased prevalence of atopy for either males or females. Further study of the relationship between obesity and allergic diseases should shed light on the complex aetiologies of the diseases and lead to new management options for allergy.

\section{Acknowledgements}

Financial support: This study was carried out as part of the project 'Implementation of the system for prevention and early diagnosis of allergic disorders in Poland' (No. 6 P05 $2005 \mathrm{C} / 06572$ ) funded by the Minister for Health and the Minister for Science. The Minister for Health and the Minister for Science had no role in the design, analysis or writing of this article. Conflict of interest: None. Authorship: B.S., F.R., A.T., A.L. and E.F.-K. conceived and carried out the experiments; A.J.S., J.K. and B.S. conceived the experiments and analysed data; A.L. and K.F. carried out the experiments; A.J.S. and B.S. conceived the data interpretation; A.S. conceived the literature search and generation of figures. All authors were involved in writing the paper and had final approval of the submitted and published versions. Ethics of buman subject participation: The study was approved by the institutional Bioethics Committee in the Centre of Postgraduate Medical Education.

\section{References}

1. Chen Y, Rennie D, Cormier Y et al. (2010) Association between obesity and atopy in adults. Int Arch Allergy Immunol 153, 372-377.

2. Beuther D \& Sutherland ER (2007) Overweight, obesity, and incident asthma a meta-analysis of prospective epidemiologic studies. Am J Respir Crit Care Med 175, 661-666.

3. Coogan PF, Palmer JR, O'Connor GT et al. (2009) Body mass index and asthma incidence in the Black Women's Health Study. J Allergy Clin Immunol 123, 89-95.

4. Gregor MF \& Hotamisligil GS (2011) Inflammatory mechanisms in obesity. Annu Rev Immunol 29, 415-445.

5. Chen Y, Dales R \& Jiang Y (2006) The association between obesity and asthma is stronger in nonallergic than allergic adults. Chest 130, 890-895.

6. Silverberg JI, Kleiman E, Lev-Tov H et al. (2011) Association between obesity and atopic dermatitis in childhood: a case-control study. J Allergy Clin Immunol 127, 1180-1186.

7. Silverberg JI, Silverberg NB \& Lee-Wong M (2012) Association between atopic dermatitis and obesity in adulthood. Br J Dermatol 166, 498-504.

8. Mitchell EA, Beasley R, Björksten B et al. (2013) The association between BMI, vigorous physical activity and television viewing and the risk of symptoms of asthma, rhinoconjunctivitis and eczema in children and adolescents: ISAAC Phase Three. Clin Exp Allergy 43, 73-84.

9. Konno S, Hizawa N, Fukutomi Y et al. (2012) The prevalence of rhinitis and its association with smoking and obesity in a nationwide survey of Japanese adults. Allergy 67, 653-660.

10. Kusunoki T, Morimoto T, Nishikomori R et al. (2008) Obesity and the prevalence of allergic diseases in schoolchildren. Pediatr Allergy Immunol 19, 527-534.

11. Visness CM, London SJ, Daniels JL et al. (2009) Association of obesity with IgE levels and allergy symptoms in children and adolescents: results from the National Health and Nutrition Examination Survey 2005-2006. J Allergy Clin Immunol 123, 1163-1169.

12. Calvert J \& Burney P (2005) Effect of body mass on exerciseinduced bronchospasm and atopy in African children. J Allergy Clin Immunol 116, 773-779.

13. Van Gysel D, Govaere E, Verhamme K et al. (2009) Body mass index in Belgian schoolchildren and its relationship with sensitization and allergic symptoms. Pediatr Allergy Immunol 20, 246-253.

14. Leung TF, Kong APS, Chan HIS et al. (2009) Association between obesity and atopy in Chinese schoolchildren. Int Arch Allergy Immunol 149, 133-140. 
15. Sybilski AJ, Raciborski F, Lipiec A et al. (2014) Epidemiology of atopic dermatitis in Poland according to ECAP study (Epidemiology of Allergic Disorders in Poland). Ann Agric Environ Med (In the Press).

16. Han JC, Lawlor DA \& Kimm SYS (2010) Childhood obesity 2010: progress and challenges. Lancet 375, 1737-1748.

17. Kułaga Z, Różdżyńska A, Palczewska I et al. (2010) Percentile charts of height, body mass and body mass index in children and adolescents in Poland - results of the OLAF study. Standardy Med 7, 690-700.

18. Weiss ST \& Shore S (2004) Obesity and asthma: directions for research. Am J Respir Crit Care Med 169, 963-968.

19. Samoliński B, Sybilski AJ, Raciborski F et al. (2009) Prevalence of asthma in children, adolescents and young adults in Poland - results of the ECAP study. Alerg Astma Immun 14, 27-34.

20. Murray CS, Canoy D, Buchan I et al. (2011) Body mass index in young children and allergic disease: gender differences in a longitudinal study. Clin Exp Allergy 41, 78-85.

21. Luo X, Xiang J, Dong X et al. (2013) Association between obesity and atopic disorders in Chinese adults: an individually matched case-control study. BMC Public Health 13, 12.

22. Tanaka K, Miyake Y, Arakawa M et al. (2011) U-shaped association between body mass index and the prevalence of wheeze and asthma, but not eczema or rhinoconjunctivitis: the Ryukyus Child Health Study. J Asthma 48, 804-810.

23. Johnston RA, Zhu M, Rivera-Sanchez YM et al. (2007) Allergic airway responses in obese mice. Am J Respir Crit Care Med 176, 650-658.
24. Yoo S, Kim HB, Lee SY et al. (2011) Association between obesity and the prevalence of allergic diseases, atopy, and bronchial hyperresponsiveness in Korean adolescents. Int Arch Allergy Immunol 154, 42-48.

\section{Appendix}

\section{Definition of allergic diseases}

Allergic diseases are defined if answers to the questions are 'yes'.

Declared asthma (DA): 'Have you ever had asthma?' Symptomatic asthma (AS): 'Have you had wheezing or whistling in your chest at any time in the last 12 months?' Allergic rhinitis (AR): 'Do you have any nasal allergies, including hay fever?'

Atopic dermatitis (AD) is defined if the answers to questions 1 and 2 and 3 are 'yes':

1. 'Have you ever had an itchy rash that was coming and going for at least 6 months?'

2. 'Have you had this itchy rash in the last 12 months?'

3. 'Has this itchy rash at any time affected any of the following places: the folds of the elbows, behind the knees, in front of the ankles under the buttocks or around the neck, ears or eyes?' 